\title{
Laparoscopic segmental resection for complete obstructive jejunal adenocarcinoma
}

\author{
D Ulaş Aday, ${ }^{1}$ (1) Faik Veysel Akpulat, ${ }^{2}$ 이 Kendal Yalçın ${ }^{3}$ \\ 'Department of Gastrointestinal Surgery, Dicle University Faculty of Medicine, Diyarbakır, Turkey \\ ${ }^{2}$ Department of Surgery, Dicle University Faculty of Medicine, Diyarbakır, Turkey \\ ${ }^{3}$ Department of Gastroenterology, Dicle University Faculty of Medicine, Diyarbakır, Turkey
}

\begin{abstract}
Small bowel adenocarcinoma (SBA) is a rare entity and surgical resection is the mainstay treatment of early-stage SBA. Laparoscopic surgery has become a well-established and popular treatment method worldwide and is known to provide numerous advantages. In this report, we present an SBA patient who developed complete obstruction of the small bowel and underwent laparoscopic segmental resection.
\end{abstract}

Keywords: Jejunal adenocarcinoma; ileus; laparoscopy.

\section{Introduction}

Small bowel adenocarcinoma (SBA) is a rare malignancy comprising less than $5 \%$ of all gastrointestinal (GI) malignancies. Its incidence increases after the age of 40 and it is mostly diagnosed in the sixth and seventh decade. Moreover, SBA is the second most common small bowel malignancy after carcinoid tumors. The current 5-year survival rate in the USA is $65.5 \%$ and the cancer stage at diagnosis has a strong influence on the length of survival. [1] SBA is challenging to diagnose, often presents at a late stage, and has a poor prognosis. Surgical resection is the mainstay treatment of early-stage SBA. ${ }^{[2]}$ Laparoscopic small bowel resection results in less operative blood loss, earlier resumption of oral diet, smaller amount of postoperative analgesic consumption, and shorter postoperative hospital stay when compared to open surgery. Moreover, laparoscopic surgery has been shown to provide similar oncological outcomes to those of open surgery. ${ }^{[3-5]}$
In this report, we investigated the utility of minimal invasive surgery in obstructive jejunal adenocarcinoma, which is a rare entity in clinical practice.

\section{Case Report}

A 74-year-old woman presented with a six-month history of a nonspecific abdominal pain and intermittent vomiting. The patient had no history of chronic diseases, drug use, or abdominal surgery. No significant findings were found in the abdominal ultrasonography (USG) and colonoscopy that were performed in another center. However, the patient had been initiated on medication due to the detection of suspicious alkaline reflux gastritis by GI endoscopy. Physical examination revealed distension and increased tympanism in the epigastric and upper left quadrant. Laboratory parameters were as follows: hemoglobin 9.5 (normal range, 12.2-18.1) $\mathrm{g} / \mathrm{dL}$, hematocrit 32\% (normal range, 37.7-53.7). No additional pathology was reported. 
Intravenous contrast-enhanced abdominal and pelvic computed tomography (CT) showed dilatation in the duodenum and proximal jejunum. Moreover, circular wall thickening encompassing $2-\mathrm{cm}$ segment of proximal jejunum was also detected. Collapsed bowel loops were observed in the distal aspect of the complete obstruction caused by this segment (Fig. 1). Decompression was applied using a nasogastric tube. The patient and her relatives were informed about the surgical procedure and a written consent was obtained. Laparoscopic exploration showed a circular mass causing complete obstruction at a location $30 \mathrm{~cm}$ distal to the Treitz ligament (Fig. 2A). No peritoneal implant or acid was observed. Following segmental meso-jejunal resection, the specimen was placed in an endobag and then removed from the abdomen through the umbilical camera port (Fig. 2B). Anastomosis was completed using the manual end-to-side suture technique. No postoperative complication was observed and the patient was discharged on postoperative day 6 . Pathological examination was reported as moderately differentiated adenocarcinoma infiltrating all layers of the bowel wall including the serosa. All the 13 lymph nodes that were dissected were reported as reactive lymph nodes

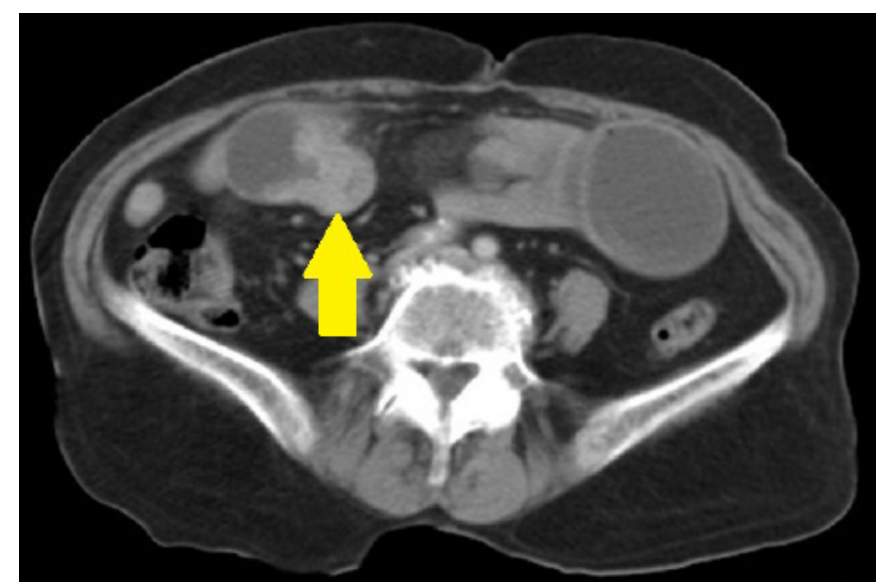

Figure 1. The view of the wall thickness increase created by the jejunal mass on axial computed tomography.
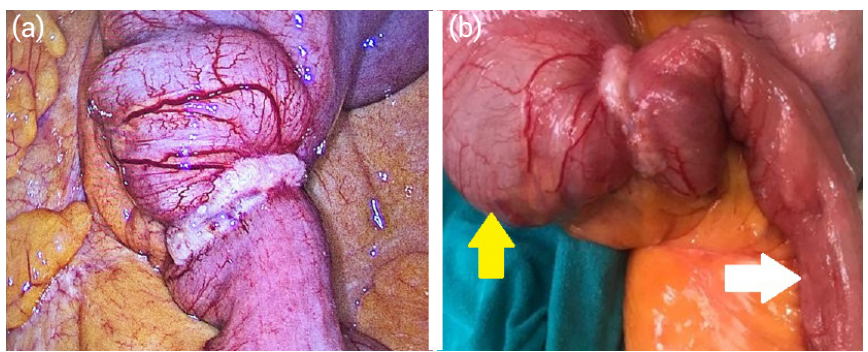

Figure 2. Laparoscopic (a) and pre-resection (b) view of the circular jejunal mass. While proximal dilatation (yellow arrow) is observed due to obstruction, the jejunum diameter is normal in the distal of the mass (white arrow).
(T3NO). The patient was followed up by the medical oncology department and was initiated on capecitabine therapy. At 6-month follow-up, the patient is free of recurrence and symptoms.

\section{Discussion}

Despite the fact that the small intestine occupies a large surface area, it is surprising that neoplasms of the small intestine are exceedingly rare, accounting for approximately $3-6 \%$ of all GI neoplasms. Almost $75 \%$ of small bowel tumors have a malignant character. ${ }^{[6,7]}$ Most patients have no known predisposing factors. However, the risk increases in Celiac and Crohn's disease, as well as familial polyposis syndromes. These tumors typically cause a nonspecific abdominal pain and weight loss or may require emergency surgical care due to obstruction, bleeding, and perforation. Intestinal obstruction is the most common clinical presentation, followed by bleeding, perforation, and detection of an abdominal mass..$^{[1,7,8]}$ Endoscopic evaluation of the small intestine is not performed in routine clinical practice except for terminal ileum and duodenum. Therefore, the detection rate of tumors is low and when they are discovered, they are frequently in advanced stages with poor long-term prognosis. ${ }^{[2,7,9]}$

Laparoscopic surgery has become a popular treatment modality for GI complications among surgeons. The potential advantages of the minimally invasive approach to small intestinal neoplasm resection include comparable surgical and oncological outcomes, decreased length of stay, cosmetically appealing scar, and improved pain scores. Additionally, it has lower rates of incisional hernia and adhesive ileus when compared to open surgery. ${ }^{[4,10,11]}$ Some difficulties are encountered in laparoscopic surgery due to obstruction-related ileus. Injuries during the insertion of the trocar, inability to achieve visualization and difficulty in manipulation are some of them. ${ }^{[12]}$ In patients who have undergone previous abdominal surgery and in fragile patients with advanced age, trocar entry should be done carefully and it should be known that laparoscopic procedure will be difficult due to midline adhesions. Exploration should be started from the collapsed intestines and should not be held with a grasper. Conversion to open should not be perceived as a failure of a laparoscopic approach, but as a normal potential course of laparoscopic surgery of SBA. ${ }^{[13]}$ Due to the rarity of small bowel adenocarcinoma, studies investigating the efficacy of adjuvant chemotherapy are limited. Nevertheless, this therapy has been shown to have a positive effect on disease-free sur- 
vival following curative resection. ${ }^{[14]}$

The case presented in the current study had a six-month history of symptoms and had developed complete jejunal obstruction prior to admission. Following nasogastric decompression, minimally invasive surgery was performed in accordance with oncological principles. The treatment was completed with the capecitabine therapy that was initiated due to the detection of Stage IIB in pathological examination.

\section{Conclusion}

Complete obstruction of the small bowel caused by jejunal adenocarcinoma is extremely rare. Laparoscopic segmental jejunal resection provides several advantages and should be preferred in selected cases.

\section{Disclosures}

Informed Consent: Written informed consent was obtained from the patient for the publication of the case report and the accompanying images.

Peer-review: Externally peer-reviewed.

Conflict of Interest: None declared.

Authorship Contributions: Concept - U.A., K.Y.; Supervision - K.Y.; Data collection and/or processing - U.A., F.V.A., K.Y.; Analysis and/ or interpretation - U.A., F.V.A., K.Y.; Literature search - U.A., F.V.A.; Writing - U.A., F.V.A., K.Y.; Critical review - U.A., K.Y.

\section{References}

1. Haselkorn T, Whittemore AS, Lilienfeld DE. Incidence of small bowel cancer in the United States and worldwide: geographic, temporal, and racial differences. Cancer Causes Control 2005;16:781-7. [CrossRef]

2. Li J, Wang Z, Liu N, Hao J, Xu X. Small bowel adenocarcinoma of the jejunum: a case report and literature review. World $\mathrm{J}$ Surg Oncol 2016;14:177. [CrossRef]

3. Tsui DK, Tang CN, Ha JP, Li MK. Laparoscopic approach for small bowel tumors. Surg Laparosc Endosc Percutan Tech 2008;18:556-60. [CrossRef]
4. Baiu I, Visser BC. Minimally Invasive Small Bowel Cancer Surgery. Surg Oncol Clin N Am 2019;28:273-83. [CrossRef]

5. Ahmed B, Weerasinghe DH, Nussbaum MS. Minimally Invasive Surgical Techniques for Cancers of the Small Intestine. In: Kim J, Garcia-Aguilar J, editors. Surgery for Cancers of the Gastrointestinal Tract. New York: Springer; 2015. [CrossRef]

6. Halfdanarson TR, McWilliams RR, Donohue JH, Quevedo JF. A single-institution experience with 491 cases of small bowel adenocarcinoma. Am J Surg 2010;199:797-803. [CrossRef]

7. Overman MJ, Hu CY, Kopetz S, Abbruzzese JL, Wolff RA, Chang GJ. A population-based comparison of adenocarcinoma of the large and small intestine: insights into a rare disease. Ann Surg Oncol 2012;19:1439-45. [CrossRef]

8. Legué LM, Bernards N, Gerritse SL, van Oudheusden TR, de Hingh IH, Creemers GM, et al. Trends in incidence, treatment and survival of small bowel adenocarcinomas between 1999 and 2013: a population-based study in The Netherlands. Acta Oncol 2016;55:1183-9. [CrossRef]

9. Young JI, Mongoue-Tchokote S, Wieghard N, Mori M, Vaccaro GM, Sheppard BC, et al. Treatment and Survival of SmalI-bowel Adenocarcinoma in the United States: A Comparison With Colon Cancer. Dis Colon Rectum 2016;59:306-15. [CrossRef]

10. Kelly KN, lannuzzi JC, Rickles AS, Garimella V, Monson JR, Fleming FJ. Laparotomy for small-bowel obstruction: first choice or last resort for adhesiolysis? A laparoscopic approach for small-bowel obstruction reduces 30-day complications. Surg Endosc 2014;28:65-73. [CrossRef]

11. Aday U, Gündeş E, Değer KC, Çiyiltepe H, Kayıpmaz Ş, Duman M. A rare cause of ileus: late jejunal stricture following blunt abdominal trauma. Ulus Travma Acil Cerrahi Derg 2017;23:74-6. [CrossRef]

12. Behman $R$, Nathens $A B$, Byrne JP, Mason S, Look Hong $N$ Karanicolas PJ. Laparoscopic Surgery for Adhesive Small Bowel Obstruction Is Associated With a Higher Risk of Bowel Injury: A Population-based Analysis of 8584 Patients. Ann Surg 2017;266:489-98. [CrossRef]

13. Behman $R$, Nathens $A B$, Karanicolas PJ. Laparoscopic Surgery for Small Bowel Obstruction: Is It Safe?. Adv Surg 2018;52:15-27. [CrossRef]

14. Kitahara $\mathrm{H}$, Honma $\mathrm{Y}$, Ueno $\mathrm{M}$, Kanemitsu $\mathrm{Y}$, Ohkawa $\mathrm{S}$ Mizusawa J. Randomized phase III trial of post-operative chemotherapy for patients with stage I/II/III small bowel adenocarcinoma (JCOG1502C, J-BALLAD). Jpn J Clin Oncol 2019;49:287-90. [CrossRef] 